\title{
PHYSICAL ACTIVITY LEVELS IN FEMALE STUDENTS OF TERNOPIL STATE MEDICAL UNIVERSITY
}

\author{
D. V. Popovych'1, J. Bergier², O. M. Sopel' ${ }^{1}$, L. S. Tsybulska', M. M. Korda' ${ }^{1}$ \\ I. HORBACHEVSKY TERNOPIL STATE MEDICAL UNIVERSITY, TERNOPIL, UKRAINE ${ }^{1}$ \\ POPE JOHN PAUL II STATE SCHOOL OF HIGHER VOCATIONAL EDUCATION IN BIALA PODLASKA ${ }^{2}$
}

Background. Lifestyle is one of the major factors in the optimal development of systems and functions of human organism and health. The appropriate level of physical activity is the integral component of a healthy lifestyle.

Objective. The study was aimed to investigate the level of physical activity of the female students of Medical University.

Methods. We applied the International Physical Activity Questionnaire (IPAQ) in the long version as a research method.

Results. The study was conducted among 333 female students of Medical University of the first, second and third year of study. Detailed International Physical Activity Questionnaire evaluating physical activity, such as work, housework, sport, and physical activity during leisure time, was completed.

Conclusions. The examined female students of medical university are characterized by high level of total physical activity. Place of residence during the studies does not differentiate significantly the level of physical activity of female students.

KEY WORDS: physical activity, the International Physical Activity Questionnaire, female students, medical university.

\section{Introduction}

Lifestyle is one of the major factors in the optimal development of systems and functions of human organism and health. Healthy lifestyle is a way of living aimed at preserving and improving state of health. The appropriate level of physical activity is the integral component of a healthy lifestyle (a natural biological need defined by the set of movements performed by a person) $[1,2]$. Many scientific studies proved the value of physical activity for the human body [3-8].

Physical activity is an integral part of man's life which largely affects the cardiovascular and muscular-bone systems of the body, and has a significant impact on body metabolism. In current living conditions people focus less on physical activity due to well-developed transporting infrastructure, sedentary work and

Corresponding author: Dariya Popovych, Department of Physical Rehabilitation, Human Health and Physical Education, I. Horbachevsky Ternopil State Medical University, 1 Maidan Voli, Ternopil, Ukraine, 46001

Phone number: +380352253669

E-mail:kozak@tdmu.edu.ua passive rest at home. Such way of live may lead to the development of various health risks. At lack of physical activity and excessive neuroemotional stress the functional state of the central nervous system, as a mediator between the muscles and internal organs, is damaged. This causes the dysfunction of individual organs and systems of the body and contributes to the development of various diseases.

The influence of physical activity on human health is widely recognized and studied among international researchers [9-13]. The issues of physical activity of students both in bio-physiological and cultural terms are more and more commonly discussed on different continents: South Asian [14], South Africa [15, 16], Europe [17-19] and in other different countries $[6,7$, 20-22], including medical universities students [23-26].

The research studies $[6,7]$ show the tendency of the decrease of physical activity among students of higher educational institutions. Therefore, the subject of our research was to 
investigate the level of physical activity of the female students of Ternopil State Medical University.

\section{Material and Methods}

The study was conducted among 333 female students of Ternopil State Medical University during October 2015. The participants were the first-, second- and third-year-students aged 17-20 years old. The total of 333 female students included: 106 first-year-students (31.83\%), 116 second-year-students (34.83\%), and 111 third-year-students (33.33\%). They were asked to complete questionnaires on demographic and general physical activity. We applied the International Physical Activity Questionnaire (IPAQ) in the long version [27] as a research method. Detailed International Physical Activity Questionnaire (IPAQ) evaluating physical activity, such as work, housework, sport, and physical activity during leisure time was completed. Dependence analyses were carried out using t-test and Pearson correlation coefficient. The level of statistical significance was adopted at $\mathrm{p}<0.05$.

\section{Results}

The results of the research have shown significantly higher level of total physical activity of female students 5590.2 MET min/week than in Poland [28] and Turkey [20]. On the basis of the International Physical Activity Questionnaire (IPAQ) it was evidenced that the activity associated with work amounted 1428.9 MET min/ week. In case of the activity associated with movement it amounted 1443.7 MET min/week. For physical activity associated with housework the results were recorded at 1162.2 MET min/ week. Physical activity in sport amounted 1555.4 MET min/week. Thus, the highest level of physical activity was identified in female students during sports workouts and the lowest during housework, but these results did not differentiate significantly (Fig. 1).

Based on the data obtained from IPAQ questionnaire on the course of study, we analysed the dynamics of physical activity during in the learning process. We established that the highest level of total physical activity of 6955.8 MET prevails in sophomores, which is by $24.42 \%$ higher than the total-level of PA, while the lowest level of total physical activity of 3855.5 MET was found in the third-year female stu dents, which is by $31.0 \%$ less than the total level of PA. Such high rate of physical activity index in the second-year-students was observed due to high levels of physical activity at work/study, which was in 2812.7 MET (40.43\%), when the index of physical activity at home was 1212.2 MET $(17.42 \%)$, in the sport - 1519.4 MET (21.84\%), and the rest - 1411.6 MET (20.29\%). However, in the third-year female students compared to the students of the first and second years of study the lowest level of physical activity during work/training of 463.3 MET (12.01\%), with activity around the house of $939.1 \mathrm{MET}(24.35 \%)$, in the sport - $1380.7 \mathrm{MET}$ (35.81\%), and the rest - $1072.4 \mathrm{MET}(27.81 \%)$ was evidenced. When comparing different types of activities of the female students, excluding physical activity during work / study, it was found that freshman have higher physical activity among students at home - 1341.3 MET, in sport - 1777.7 MET, and the rest - 1867.6 MET,

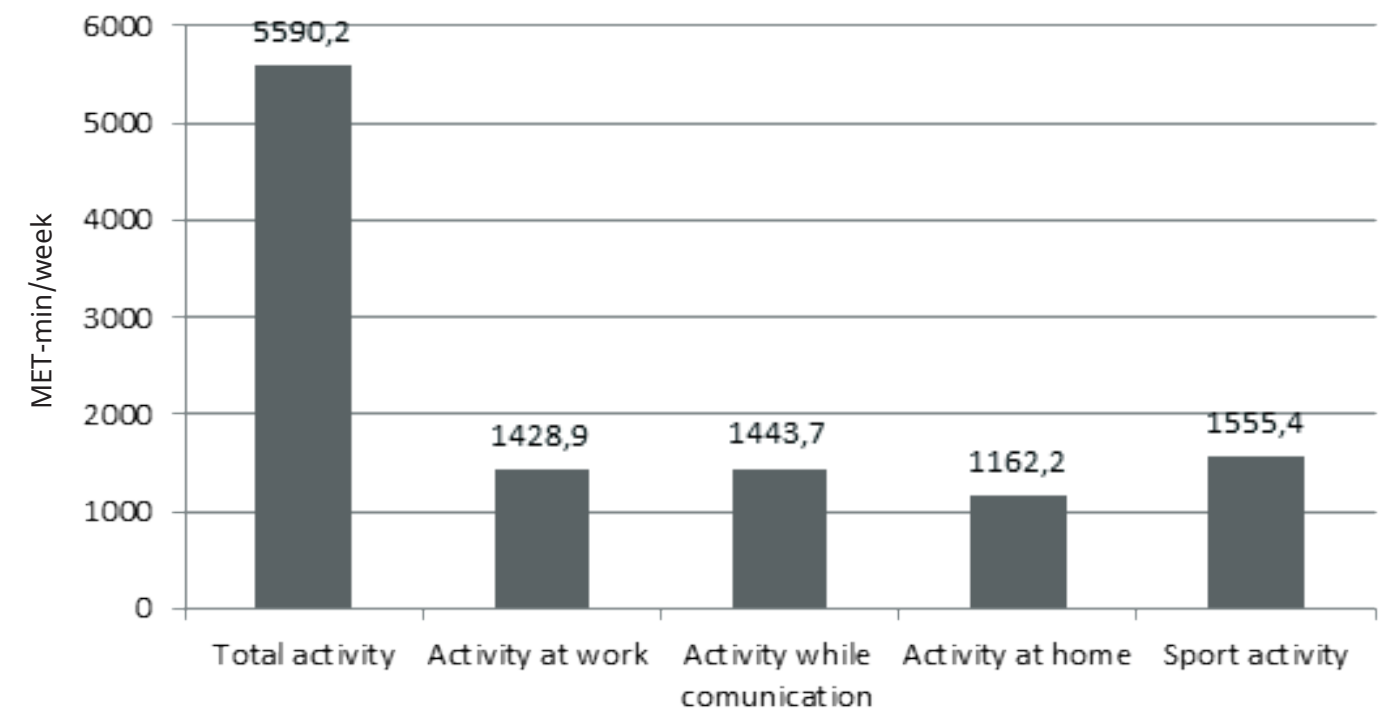

Figure 1. The level and areas of physical activity of the female students 
than the second- and third-year female students, which have the lowest physical activity in all types of physical activity (Fig. 2, Table 1).

We found it interesting to discover whether the place of living of the recipients influence upon the level of their physical activity. Three places of residence were used for the analysis: dormitory, family home and parents' apartment. Also this combination showed no significant differences in the total physical activity of the female students depending on the place of daily residence (Fig. 3, Table 2).

\section{Discussion}

As a result of our research we have discovered a high level of overall physical activity in female students of Medical University (55902 MET min/week). After analysing the dynamics of physical activity of female students depending on the year of study we have found out that the highest overall physical activity (6955.8 MET) prevailed in the second-year students. Such high rate of physical activity in sophomores was due to high level of physical activity at work/ study (it was $40.43 \%$ of the total recipients of physical activity). This fact can be explained by the location of university departments and buildings, where classes for the second-yearstudents took place and by the lack of direct transportation between those locations. The average level of physical activity at the work/ school is 463.3 MET in the third-year-students and it may explained by the increased duration of classes. In all other areas of physical activity (work, at home, leisure or sport) students showed high level of the researched activity, but it tended to slight decrease from the first to the third year of study. As for the residence of students, no direct connection between the place of residence (dormitory, apartment or parents' house) and the physical activity was found [17].

Thus, we can assume that regardless of the year of study and the place of residence the main factor of physical activity type among the female students of medical university is their correct (common sense) understanding of the role of this factor in a healthy lifestyle.

However, is should be emphasised that a questionnaire is the cheapest method of collec-

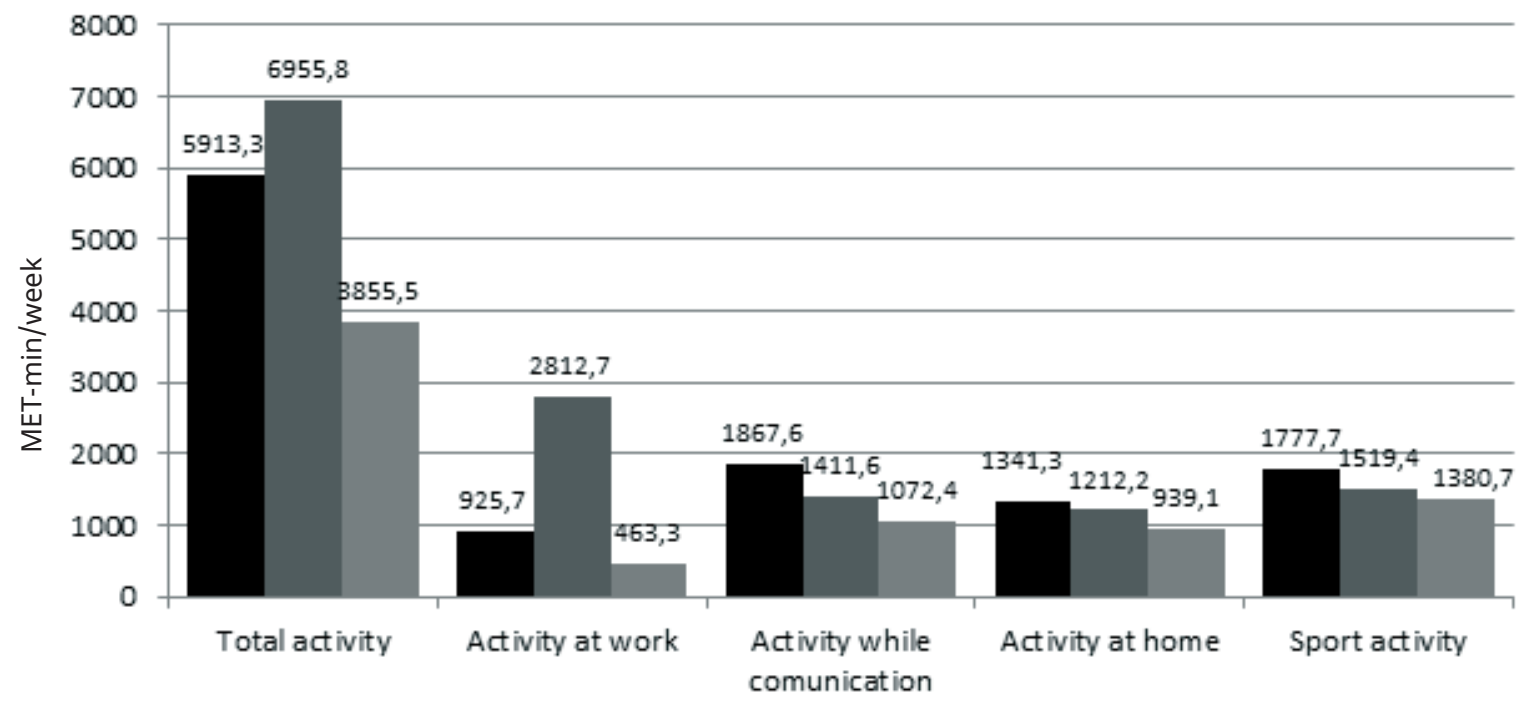

$\square \square 2 \square 3$

Figure 2. The level and areas of physical activity of the female students with regard to the year of study

Table 1. The differentiation of the level and areas of physical activity of the female students with regard to the year of study

\begin{tabular}{|l|c|c|c|}
\hline \multicolumn{3}{|c|}{ Kruskal-Wallis Test } \\
\hline \multicolumn{1}{|c|}{ Physical Activity Type } & $\mathrm{H}$ & $\mathrm{p}$ & Differentiation \\
\hline Total activity & 29,47 & $0,0001^{*}$ & $1-3 ; 2-3^{*}$ \\
\hline Activity at work & 38,21 & $0,0001^{*}$ & $1-2,3 ; 2-3^{*}$ \\
\hline Activity while commuting & 14,30 & $0,0008^{*}$ & $1-3^{*}$ \\
\hline Activity at home & 7,84 & $0,0198^{*}$ & $1-3^{*}$ \\
\hline Sport activity & 8,47 & $0,0145^{*}$ & $1-3^{*}$ \\
\hline
\end{tabular}

Note. * - significant differences at $p<0,05 ; * *$-years of study between which there is a statistically significant variation. 


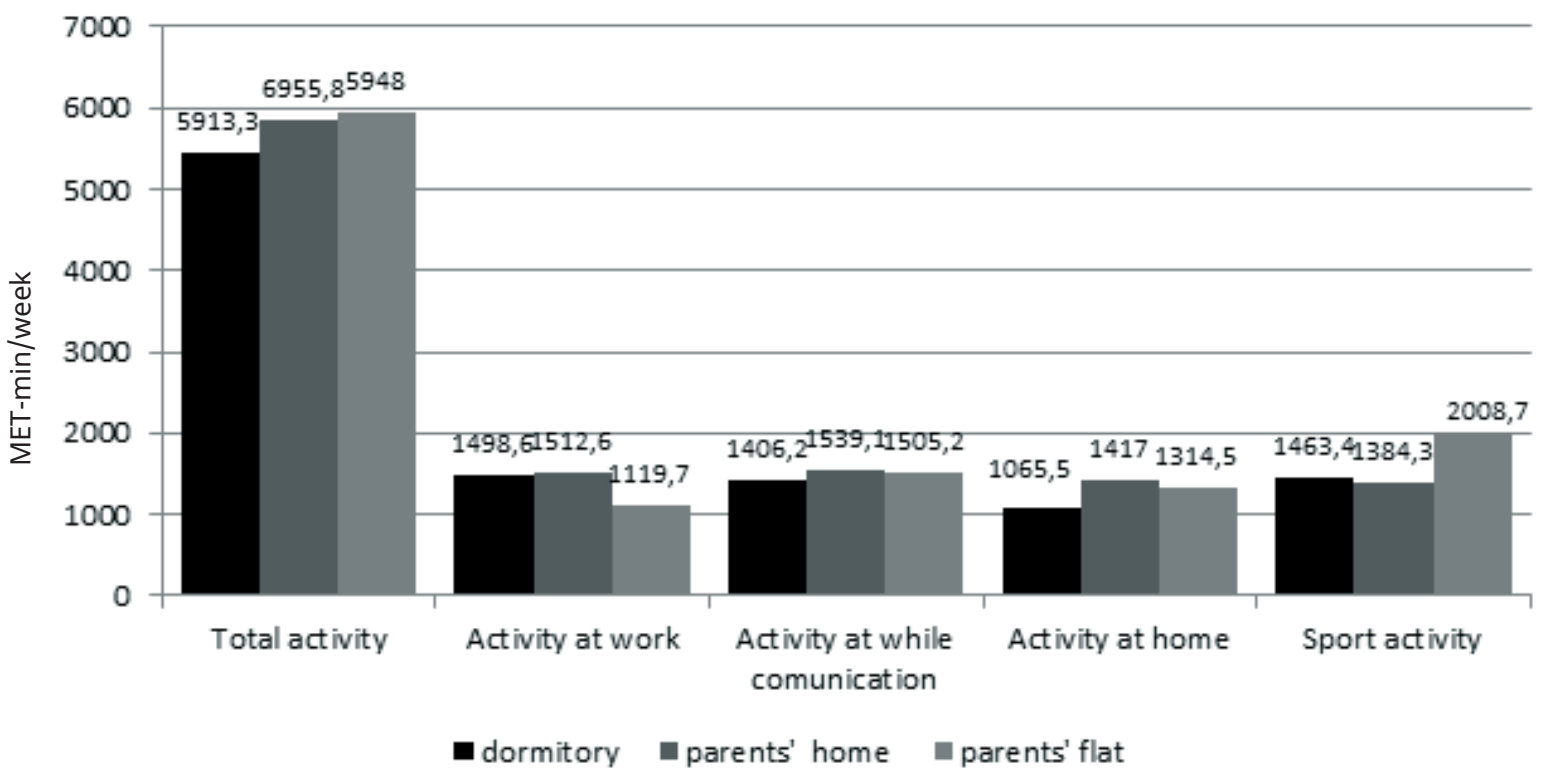

Figure 3. The level and areas of physical activity of the female students with regard to the place of residence

Table 2. The differentiation of the level and areas of physical activity of the female students with regard to the place of residence

\begin{tabular}{|l|c|c|c|}
\hline \multicolumn{3}{|c|}{ Kruskal-Wallis Test } \\
\hline \multicolumn{1}{|c|}{ Physical activity Type } & $\mathrm{H}$ & $\mathrm{p}$ & Differentiation \\
\hline Total activity & 0,32 & 0,8505 & - \\
\hline Activity at work & 0,58 & 0,7477 & - \\
\hline Activity while commuting & 0,11 & 0,9484 & - \\
\hline Activity at home & 2,03 & 0,3616 & - \\
\hline Sport activity & 5,14 & 0,0767 & - \\
\hline
\end{tabular}

ting data on a large number of respondents (national and international research) regardless of their sex, age or health [29].

\section{Conclusions}

The female students of medical university are characterized by high level of total physical activity compared with the male students.
The highest level of total physical activity prevails in the second-year female students.

The place of residence during the studies (dormitory, family house or apartment) does not differentiate significantly the level of physical activity of the female students.

\section{References}

1. Krutsevych TYu, Bezverhnya HV. Recreation in physical culture at different groups population. Kyiv: Olympiyskaya literatura 2010; 248.

2. Rybkovskyy AG, Kanishevsky PM. System organization of human motor activity 2003; 436 p.

3. Balsevich VK, Zaporozhanov VA. Physical activity of a person. Health 1987; 224.

4. Dubogay A, Yevtushok M. The nature and impact of school innovation in Health-System technology. Physical education, sport and culture of health in modern society $2008 ; 1$ : 36-40.
5. Roviy AS, Rovno VA, Rovno AA. Physiology of motor activity. Kharkov 2014; 344.

6. Tsos AV, Kasarda OZ, Shevchuk AB, Samchuk AN, Khomich AV. Special physical activity of students of higher educational institutions. Modern problems of health and healthy lifestyle athletic education 2015; 129: 330-334.

7. Bergier B, Tsos A, Bergier J. Factors determining physical activity of Ukrainian students. Annals of Agricultural and Environmental Medicine 2014; 21: 613-616. 
8. Nowak MA, Troczyńska N, Forjasz J, Nowak L. Chosen aspects of lifestyles of physical activity women aged 45-59 and 60-74. Health Problems of Civilization 2016; 10 (3): 30-37.

9. Cavil N, Biddle S, Sallis JF. Health enhancing physical activity for young people. Statement of the United Kingdom expert consensus conference. Pediatric Exercise Science 2001; 13:12-25.

10. Paffenbarger RS, Lee IM. A natural history of athleticism, health and longevity, fournal of Sports Sciences 1998; 16: 31-45.

11. Powell KE, Bricker SK, Blair SN. Treating inactivity. American Journal of Preventive Medicine 2002; 23: 1-2.

12. Warburton DER, Nicol C, Bredin SSD. Health benefits of physical activity: the evidence. Canadian Medical Journal 2006; 174 (6): 801-809.

13. Chastin SFM, Dall PM, Tigbe WW, Grant MP, Ryan CG, Rafferty D, Granat MH. Compliance with physical activity guidelines in a group of UK-based postal workers using an objective monitoring technique. European Journal of Applied Physiology 2009; 106: 893-899.

14. Shani D, Nimbalkar A, Phatak A, Nimbalkar S. Training in dietary practices and physical activity to improve health among South Asian medical students. Advances in Preventive Medicine 2014; http:// dx.doiorg/10.1155/2014/610180

15. Bioemhoff HJ. Gender and race-related physical activity levels of South African university students. African Journal for Physical, Health Education, Recreation and Dance AJPHERD 2010; 16(41): 25-35.

16. Pengpid S, Peltzer K. Physical inactivity and associated factors among university students in South Africa. African Journal for Physical, Health Education, Recreation and Dance APHERD 2013; 19 (I): 143-53.

17. Bergier I, Kapka Skrzypczak L, Bilinski P, Paprzycki P, Wojtyta A. Physical activity of Polish adolescents and young adults according to IPAQ: a population based study. Ann Agric Environ Med 2012; 19: 109-115.

18. Baar J, Romppel M, Igel D. Associations between the residential environment and physical activity in german college students and the role of self-efficacy as a mediator. Zeitschrift fur Gesundheitspsychotogie 2014; 22(3): 118-128.
19. Pedisic Z, Rakovac M, Bennie J, Jurakic D, Bauman AE. Levels and correlates of domain-specific physical activity in university students: Crosssectional findings from Croatia. Kinesiology 2014; 46(1): 12-22.

20. Soguksu K. Physical activity level between Polish and Turkish university students (IPAQ). In: Bergier B, editor. Physical activity in health and disease. Biata Podlaska: Pope John Paul II State School of Higher Education in Biata Podlaska 2011; 19-27.

21. Zhao Y, Sigmunt E, Sigmundova D, Lu Y. Comparison of physical activity between Olomouc and Beijing University students using an international physical activity questionare. Acta Univ Palacki Olomuc Gymn 2007; 37(4): 107-114.

22. Haase A, Steptoe A, Sailis F, Wardle J. Leisuretime physical activity in University students 23 countries: associations with health beliefs, risk awareness, and national economic development. Prev Med 2004; 39 (1): 182-90.

23. Buchman BP, Sallis JF, Criqui MH, Dimsdale JE, Kaplan RM. Physical activity, physical fitness, and psychological characteristics of medical students. J. Psychosom Res 1991; 35: 197-208.

24. Lobelo F, Duperly J, Frank E. Physical activity habits of doctors and medical students influence their counselling practices. Br. Sports Med 2009; 43: 89-92.

25. Stanford FC, Durkin MW, Blair SN, Powell CK, Poston MB, Stallworth JR. Determining levels of physical activity in attending physicians, resident and fellow physicians and medical students in the USA. $\mathrm{Br}$ J.Sports Med. 2012; 46: 360-364.

26. Dabrowska-Galas M, Plinta R, Dqbrowska J, Skrzypulec-Plinta V. Physical activity in students of the Medical University of Silesia in Poland. Phys Ther 2013; 93 (3): 384-392.

27. Booth ML. Assessment of physical activity: An International Perspective. Res. Quart. Exerc. Sport 2000; 71: 114-120.

28. Biernat E. Aktywność fizyczna mieszkańców Warszawy na przykładzie wybranych grup zawodowych. Szkoła Główna Handlowa, Urząd m. st. Warszawy. Biuro Sportu i Rekreacji, Warszawa, 2011.

29. Biernat E. International Physical Activity Questionnaire. Polish long version. Polish Journal of Sports Medicine 2013; 29 (1): 1-15. 